\title{
A CARACTERIZAÇÃO DA PRECIPITAÇÃO DO ANO HIDROLÓGICO DE 2013-2014 NA REGIÃO DE SÃO CARLOS/SP E SUA REPERCUSSÃO NO ESPAÇO GEOGRÁFICO
}

\author{
SANTOS, Bruno César dos - bruno-unifal@hotmail.com \\ Universidade de São Paulo/USP \\ SOUZA, Paulo Henrique de - phsouza31@hotmail.com \\ Universidade Federal de Alfenas / UNIFAL \\ VECCHIA, Francisco Arthur da Silva - fvecchia@sc.usp.br \\ Universidade de São Paulo/USP
}

\begin{abstract}
RESUMO: A região Sudeste do Brasil apresenta um padrão climático oriundo da localização geográfica que possui e influência exercida pelos sistemas atmosféricos que atuam e predominam em seus domínios, estabelecendo uma sucessão habitual dos tipos de tempo inerentes à sazonalidade que caracteriza o Clima Tropical. Sujeito a essa conjuntura, a área de estudo, situada no interior do Estado de São Paulo apresenta índices pluviométricos médios situados próximos a $1.500 \mathrm{~mm}$ anuais, ainda que a sazonalidade de seu clima concentre a maior parte dessa precipitação no período situado entre os meses de outubro a março. Nesse quadro, onde a passagem de frentes e 0 processo de frontogênese respondem pelo "input" hídrico, a localidade (São Carlos/SP) encontra-se inserida, beneficiando-se da orografia que possui (reverso das Cuestas Basálticas) para apresentar índices pluviométricos ligeiramente superiores. Atentando para estas informações, o presente estudo procurou descrever e analisar o ano hidrológico de 2013-14 frente à distribuição sazonal da precipitação dos últimos 21 anos, tomados seis meses chuvosos, e, igualmente, denominados como ano hidrológico. A partir daí, buscou avaliar seu padrão diante dos totais de chuva desse período para classificação de seu índice sob os parâmetros admitidos para meses secos, chuvosos ou habituais. A metodologia foi aplicada também para a série histórica frente sua habitualidade e Anos-Padrão. Conforme os dados evidenciaram, o ano estudado apresentou índice pluviométrico significativamente abaixo da média, com distribuição irregular da precipitação durante o período chuvoso.
\end{abstract}

Palavras- chaves: Clima, Anos Padrão, Ano Hidrológico, Precipitação, Atmosfera

THE CHARACTERIZATION OF THE PRECIPITATION IN THE 2013-2014 HYDROLOGICAL YEAR IN THE REGION OF SÃO CARLOS / SP AND ITS REPERCUSSION IN THE GEOGRAPHICAL SPACE

ABSTRACT: The Southeast region of Brazil exhibits a climatic pattern derived from its geographic location and an influence exerted by the atmospheric systems that act and predominate in its domains, establishing a habitual succession of the types of weather inherent to the seasonality that characterizes the Tropical Climate. Subject to this situation, the study area, located in the interior of the State of São Paulo, retains average annual rainfall indexes of approximately $1,500 \mathrm{~mm}$, although the seasonality of its climate concentrates most of this precipitation in the period between October and March. In this context, where the passage of weather fronts and the frontogenesis process account for the water input, the locality (São Carlos/SP) is inserted, benefiting from the orography that it bears (reverse of the Basaltic Cuesta) to exhibit slightly higher pluviometric indexes. Considering this information, the present study sought to describe and analyze the hydrological year of 2013-14 in face of the seasonal distribution of precipitation of the last 21 years, adopting six rainy months, also referred to as the hydrological year. From then on, the authors attempted to evaluate its pattern regarding total rainfall during this period in order to classify its index under the accepted parameters for dry, rainy or typical months. This methodology was also applied to the historical series with respect to its regularity and Standard Years. As evidenced by the 
data, the studied year contributed to a rainfall index significantly below average, with irregular distribution of precipitation during the rainy season.

Keywords: Climate, Standard Years, Hydrological Year, Precipitation, Atmosphere.

\section{INTRODUÇÃO}

A influência climática em um determinado lugar está ligada ao comportamento dinâmico atmosférico, manifesto pelos seus atributos (temperatura, precipitação, pressão atmosférica, umidade relativa) através de uma habitualidade que determina um ritmo capaz de influir na paisagem, bem como afetar as relações entre o homem e o ambiente dentro de um espaçotempo determinado.

Por conseguinte, dada a magnitude e abrangência de seus fenômenos, André (2006) entende que o clima exerce uma função destacada na configuração do espaço geográfico e na formação do meio ambiente, tornandose determinante na disponibilidade de alguns recursos naturais e nas características gerais da paisagem, assim como nos aspectos socioeconômicos e culturais oriundos a partir da presença humana numa determinada área.

Dentre as manifestações de um tipo climático, a precipitação, através de sua intensidade e frequência ao longo de um ano, responde por parte dos parâmetros que o descrevem por estar sujeita a conjugação das forças atmosféricas que prevalecem sobre uma determinada região. Obviamente esse padrão atmosférico é definido e estabelecido após a análise dinâmica de suas variáveis climatológicas por uma duração de tempo considerável que permite a identificação dos seus padrões habituais (NIMER, 1979).

Monteiro (1973) ao estudar o comportamento das chuvas no território paulista, demonstrou a necessidade da climatologia recorrer à dinâmica atmosférica, sem a interpretação de fatos isolados, mas com uma combinação diária e simultânea dos diferentes elementos do clima e do seu ritmo de sucessão habitual para conseguir descrevê-lo a partir da compreensão da gênese dos fenômenos atmosféricos que o definem naquela porção do espaço geográfico.

Sob esse embasamento o presente estudo foi desenvolvido numa porção do município de São Carlos situada na região Centro-Leste do estado de São Paulo e submetida a uma configuração atmosférica classificada como Tropical, onde são identificadas, a grosso modo, duas estações no ano; uma seca com temperaturas menos elevadas e outra chuvosa com temperaturas elevadas. Segundo Cunha (1997) essa umidade é resultante da organização sinótica dos sistemas atmosféricos produtores do tempo que agem sobre seus domínios através do processo de frontogênese e se concentra ao longo da estação quente, exercendo um papel importante sobre a flora e fauna, bem como, para vida e atividades humanas. Obviamente a essa contribuição soma-se o volume proporcionado pela precipitação orográfica advinda da topografia específica da área e pelos processos convectivos que se estabelecem no período mais quente e úmido do ano. Os episódios excepcionais ocorridos na área de estudo são analisados também pela possibilidade de denunciarem alterações significativas na habitualidade do regime de chuvas que se encontra estabelecido conforme as sazonalidades históricas registradas ao longo de sua série temporal. 
Aliás, durante a primavera-verão de 2013/2014, ao contrário do que costuma acontecer habitualmente nessa época do ano, poucos sistemas frontais conseguiram alcançar o Brasil e a Zona de Convergência do Atlântico Sul, responsável pelo escoamento de umidade da Amazônia para o Sudeste não ocorreu de maneira habitual (CENTRO DE PREVISÃO DO TEMPO E ESTUDOS CLIMÁTICOS - CPTEC, 2014). Isso gerou grande escassez na precipitação, aumento da temperatura no Sudeste do Brasil, causando diversos problemas nos setores de abastecimento de água, reposição de água nos reservatórios e também no meio ambiente.

Obviamente tal conjuntura alerta para a necessidade urgente de ser adotado e implementado um planejamento territorial capaz de minimizar para qualquer sociedade os impactos negativos advindos com essa situação, permitindo que a qualidade de vida da população não seja afetada, bem como o exercício de suas atividades habituais, pois, via de regra, a inexistência de estratégias eficazes de mitigação e preparo para os problemas advindos das situações de escassez hídrica acaba por favorecer a dilapidação dos recursos naturais e o comprometimento dos diversos ecossistemas. Em face disto, planejar ações para lidar com esses cenários que destacam a relevância das questões hídricas, inserindo no contexto a geração de energia, a indústria e o turismo, entre outras atividades socioeconômicas, torna-se imperativo (CARMO et al., 2014).

Diante disto, a presente pesquisa analisou a precipitação na área de estudo concentrada nos seis meses mais chuvosos (outubro a março) do ano de duas estações climatológicas com uma série histórica de vinte e um anos, utilizando a metodologia de Anos-Padrão e o desvio da média que classifica os períodos em cinco modalidades - Normal, Chuvoso, Tendente a Chuvoso, Seco, e, Tendente a Seco. Também procurou caracterizar o semestre hidrológico de 2013-2014, segundo a referida classificação, destacando ainda toda repercussão que a oscilação no índice pluviométrico da área causou no seu espaço geográfico por meio da consulta aos registros feitos nos jornais da região.

\section{MATERIAIS E MÉTODOS}

No presente estudo foi utilizado tratamento quantitativo dos dados de precipitação diária em duas séries históricas, que corresponde a um registro de vinte e um anos (1993-1994 a 2013-2014), adquiridos nas estações climatológicas localizadas na Universidade Federal de São Carlos (UFSCar), pertencente ao Instituto Nacional de Meteorologia (INMET) sob as coordenadas: 21058'48" (S) e 47053'02" (O), numa altitude de 856m e na Empresa Brasileira de Pesquisa Agropecuária (EMBRAPA/Sudeste) nas coordenadas: 21057'42" (S) e 47050'28" (O), numa altitude de $860 \mathrm{~m}$, no município de São Carlos-SP (Figura $1)$. 


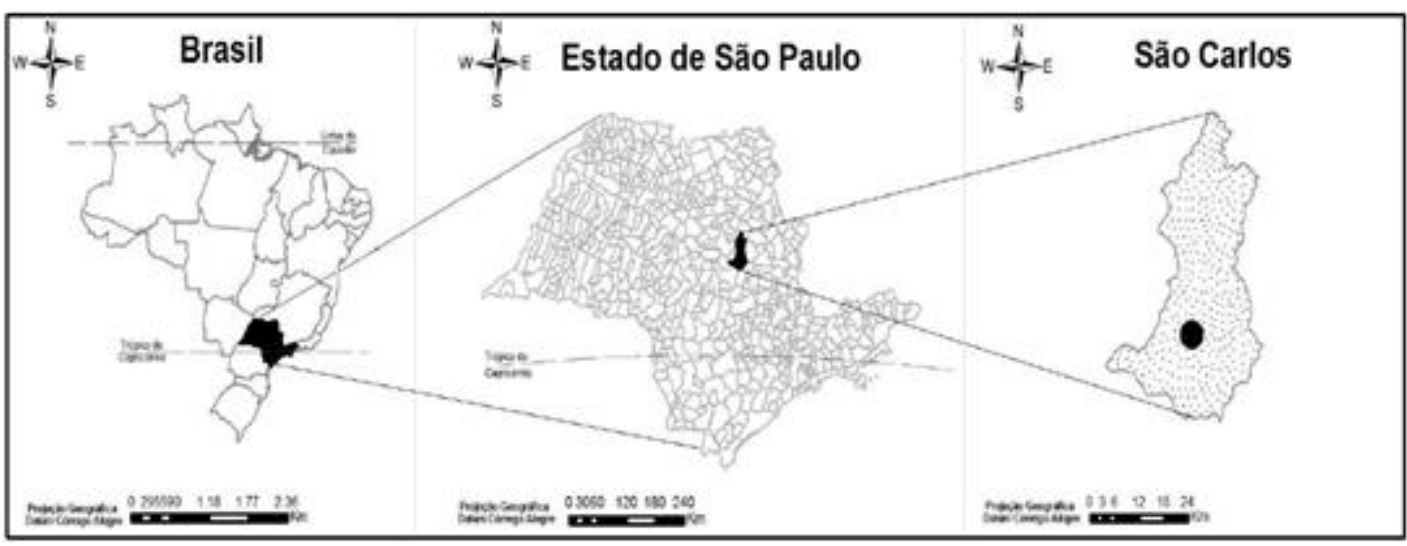

Figura 1 - Localização da Área de Estudo.Fonte: Neves (2014, p.41)

Os dados coletados referentes aos últimos 21 anos hidrológicos foram divididos e analisados por meio de tempos sucessivos representativos mensais, sazonais e anuais.

Posteriormente, foram elaboradas tabelas e gráficos com os registros pluviométricos do período com 0 intuito de facilitar a visualização da variabilidade pluviométrica. A primeira etapa constituiu-se na tabulação da série histórica do período obtida nos 21 anos hidrológicos de outubro a março 19931994 a outubro a março 2013-2014.

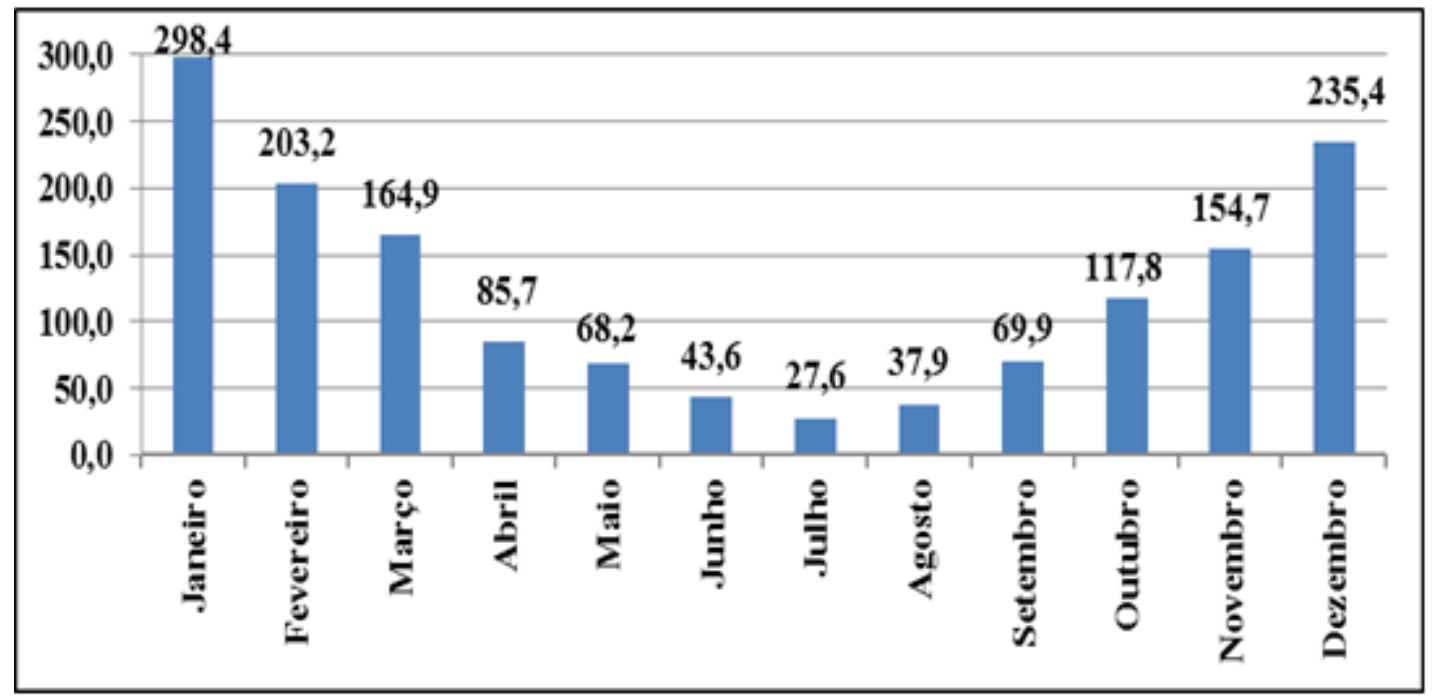

Gráfico 1 - Médias pluviométricos mensais de São Carlos (1961/1990). Fonte: Instituto Nacional de Meteorologia - INMET (2017).

A etapa seguinte do trabalho ocupou-se com o tratamento estatístico dos dados de precipitação, utilizando-se os respectivos parâmetros - média, desviopadrão e coeficiente de variação - admitidos para escalas de análise mensal, sazonal e anual. Também foram caracterizados os anos hidrológicos por meio da metodologia da classificação de "anos padrões" proposta por Monteiro (1976), ou seja, "os diferentes graus de proximidade do ritmo "habitual" ao lado daqueles afetados por irregularidades na circulação" (MONTEIRO, 1991, p.38), 
classificando-os como habitual (Normal) ou atípico (Seco ou Chuvoso), conforme a Tabela 1.

De acordo com Tavares (1976), os valores de precipitação que apresentarem desvios próximos da média serão considerados anos habituais, e, aqueles que adquiriram grandes desvios positivos em relação às médias caracterizam anos chuvosos, e, os de grande desvio negativos anos secos. Essa classificação de Anos Padrões já foi utilizada na busca da compreensão do regime pluviométrico em diversos trabalhos (BARBOSA, J. P. M., 2007; BRAIDO \& TOMMASELLI, 2010; MOURA \& ZANELLA, 2012; SILVA \& SILVA, 2012; SOARES \& ZANELLA, 2014), que buscaram determinar padrões pluviométricos (habituais e excepcionais) em diversas escalas temporais, a fim de demonstrar a variabilidade climática, neste caso a precipitação, em relação à bacia hidrográfica, produção agrícola e sobretudo no espaço delimitado para cada região geográfica.

Cumpre destacar que tal metodologia não discute pontualmente ocorrências que se manifestam em períodos curtos de vinte e quatro horas, recobrando, por conseguinte, uma atenção maior do pesquisador no cuidado de eventos que por vezes possam ser mais significativos que a média mensal avaliada.

Ao aplicar-se a metodologia de Monteiro (1976), com objetivo de classificar os anos hidrológicos que se demonstraram habituais ou atípicos e, assim, verificar ao longo das séries históricas a manifestação desses parâmetros, cuidou-se em avaliar também a precipitação do ano hidrológico de 2013-2014.

Para isso, foi calculado a média, o desvio padrão, e, como determinado, a variação das chuvas ao longo da série histórica para cada ano hidrológico (outubro a março), analisado em duas estações climatológicas, dando visibilidade à variabilidade das chuvas ao longo tempo, assim como a frequência de cada classe admitida. Por último, foi apresentado por meio de reportagens, as repercussões geradas no setor socioambiental da região de São Carlos/SP no ano hidrológico de 2013-2014.

Tabela 1 - Classificação do comportamento pluviométrico

\begin{tabular}{|lr|}
\hline Classificação & Desvios (+) ou (-) em \% \\
\hline Normais: & desvios variando entre $+15 \%$ e $-15 \%$ \\
\hline Tendentes a Secos: & desvios negativos oscilando entre $15 \%$ a $30 \%$ \\
\hline Secos: & desvios negativos superiores a $30 \%$ \\
\hline Tendentes a Chuvosos: & desvios positivos oscilando entre $15 \%$ a $30 \%$ \\
\hline Chuvosos: & desvios positivos superiores a $30 \%$ \\
\hline
\end{tabular}

Fonte: Adaptado de Monteiro (1976) 


\section{RESULTADOS E DISCUSSÕES}

\section{INMET/UFSCar}

Os dados de precipitação da série histórica obtidos na Estação Meteorológica do INMET/UFSCar, que correspondem a um período de 21 anos hidrológicos, apresentaram uma média de 1225,46 mm. Seus resultados apontaram para uma variabilidade no comportamento pluviométrico do período (Gráfico 2).

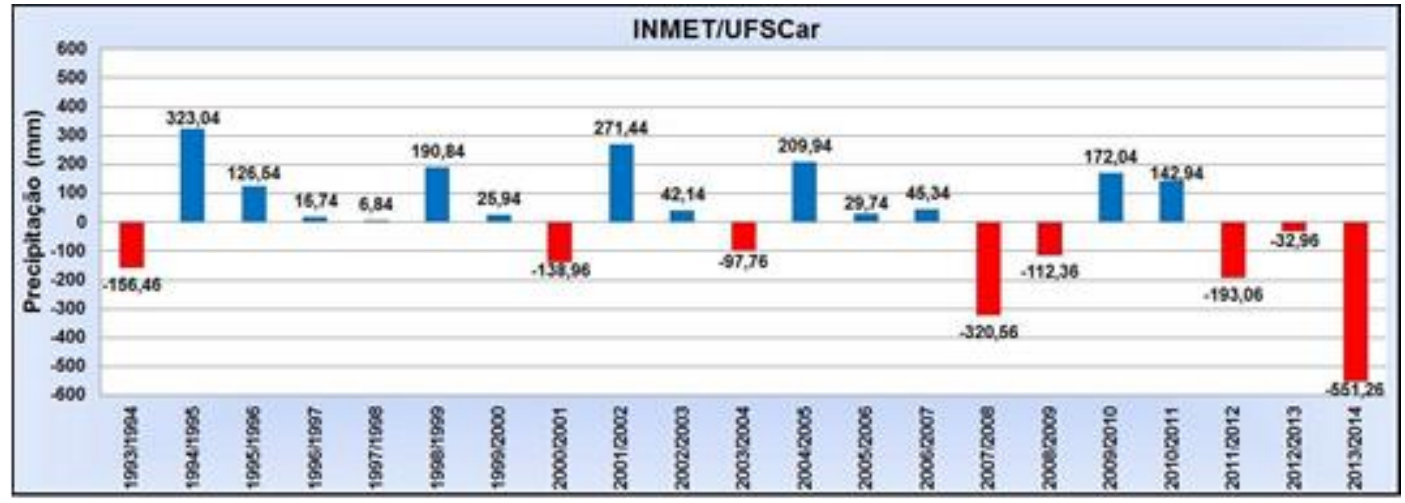

Gráfico 2 - Desvios em relação à média dos dados pluviométricos registrados na Estação Sinótica do INMET/UFSCar no período de 1993/94 a 2013/14.

Segundo Peixoto (1987, p.15), "a variabilidade climática refere-se a intervalos de tempo a que se pode associar uma causa definida menor e incluir os valores extremos e as diferenças entre valores médios anuais, sazonais, mensais". Nos dados apresentados no gráfico 2 é possível observar, ao longo do tempo, momentos em que a precipitação apresentou valores com desvios positivos, negativos e extremos da precipitação sem, contudo, evidenciar uma sazonalidade caracterizada por períodos de retorno.

Essa análise da variabilidade das chuvas nos 21 anos hidrológicos (1993/1994 a 2013/2014) delimitou a frequência que os semestres apresentaram categorias dentro das classificações (Normal, Seco ou Chuvoso), e assim, identificou que situação foi preponderante sobre as demais, assim como a porcentagem pluviométrica de cada um dos intervalos adotados dentro da série temporal. O mesmo foi feito em específico com o período chuvoso de 2013/2014 diante das categorias adotadas.

Desta maneira, observou-se nos dados analisados que possuiu maior ocorrência ao longo da série de 1993/1994 a 2013/2014 o intervalo classificado como Anos Normais (N) com índices pluviométricos situados dentro dos desvios admitidos entre $-15 \%$ e $+15 \%$, da média, a saber os anos de 1993/1994, 1995/1996, 1996/1997, 1997/1998, 1999/2000, 2000/2001, 2002/2003, 2003/2004, 2005/2006, 2006/2007, 2008/2009, 2009/2010, 2010/2011, e 2012/2013, alcançando um total de 14 manifestações na série temporal considerada, respondendo percentualmente por dois terços dos anos constituintes desse período de 21 anos.

A segunda ordem de frequência foram os semestres que apresentaram valores com desvios positivos variando entre $+15 \%$ e $+30 \%$ em relação à média, e, são classificados como Tendente a Chuvoso (TC), desta classe fizeram 
parte os anos de 1994/1995, 1998/1999, 2001/2002 e 2004/2005, ocorrendo 4 vezes ao total, e assim, representando percentualmente $19 \%$ do período.

No terceiro posto das ocorrências, com desvios negativos entre $-15 \%$ e $30 \%$ da média e classificados como Tendentes a Seco (TS) foram identificados os anos de 2007/2008 e 2011/2012 com um total de 2 vezes e alcançando percentualmente $9,52 \%$ da série histórica.

Por último, a quarta maior ordem de frequência ficou a classificação Ano Seco (S) com uma manifestação e participação percentual de $4,76 \%$ do total de anos considerados.

A Tabela 2 a seguir apresenta de forma sintetizada o número de ocorrências para cada classe admitida na metodologia de estudo adotada na pesquisa.

Tabela 2 - Frequência porcentual dos tipos de classificação (1993/1994 - 2013/14)

\begin{tabular}{|l|c|c|c|}
\hline \multicolumn{1}{|c|}{ Tipo } & $\begin{array}{c}\text { Número de } \\
\text { Ocorrências }\end{array}$ & Porcentagem & $\begin{array}{c}\text { Ordem de } \\
\text { Frequência }\end{array}$ \\
\hline N - Normais & 14 vezes & $66,66 \%$ & 10 \\
\hline TC - T. Chuvosos & 4 vezes & $19,04 \%$ & 20 \\
\hline C - Chuvosos & 0 vez & $0 \%$ & 00 \\
\hline TS - T. Secos & 2 vezes & $9,52 \%$ & 30 \\
\hline S - Secos & 1 vez & $4,76 \%$ & $4^{\circ}$ \\
\hline
\end{tabular}

Segundo a estação do INMET/USFCar registrou, o período chuvoso de $2013 / 2014$ apresentou um total de $674,2 \mathrm{~mm}$, classificando-se como Ano Seco (S) por seu desvio negativo frente a média obtida para a série.

Ao longo dos 21 anos da série não foi identificada situação semelhante àquela que se observou no período chuvoso de 2013/2014, pois, além deste ano, apenas dois anos (2007/2008 e 2011/2012) apresentaram valores negativos, porém, ficando classificados como semestres "Tendentes a Seco" (TS). Aliás, além desse semestre atípico Seco, não foi identificado nenhum semestre atípico Chuvoso na série, ainda que alguns anos tenham se destacado pelos valores dos desvios positivos que apresentaram como é o caso dos anos de 1994/1995, 1998/1999, 2001/2002 e 2004/2005 que ficaram classificaram como anos "Tendente a Chuvoso". 
Tabela 3 - Classificação dos anos e seus padrões para estação INMET/UFSCar

\begin{tabular}{|c|c|c|c|c|}
\hline ANOS & TOTAL & \multicolumn{3}{|c|}{ Classificação } \\
\hline $\begin{array}{l}\text { MÉDIA (1993-94/2013-14) Est. } \\
\text { INMET/UFSCar }\end{array}$ & 1211 & (TS) & $(\mathrm{TC})$ & (C) \\
\hline Primavera-Verão - 2013/2014 & 674,2 & \multicolumn{3}{|c|}{ Seco (S) } \\
\hline Primavera-Verão - 2012/2013 & 1192,5 & \multicolumn{3}{|c|}{ Normal (N) } \\
\hline Primavera-Verão - 2011/2012 & 1032,4 & \multicolumn{3}{|c|}{ Tendente a Seco (TS) } \\
\hline Primavera-Verão - 2010/2011 & 1368,4 & \multicolumn{3}{|c|}{ Normal (N) } \\
\hline Primavera-Verão - 2009/2010 & 1397,5 & \multicolumn{3}{|c|}{ Normal (N) } \\
\hline Primavera-Verão - 2008/2009 & 1113,1 & \multicolumn{3}{|c|}{ Normal $(\mathrm{N})$} \\
\hline Primavera-Verão - 2007/2008 & 904,9 & \multicolumn{3}{|c|}{ Tendente a seco (TS) } \\
\hline Primavera-Verão - 2006/2007 & 1270,8 & \multicolumn{3}{|c|}{ Normal (N) } \\
\hline Primavera-Verão - 2005/2006 & 1255,2 & \multicolumn{3}{|c|}{ Normal (N) } \\
\hline Primavera-Verão - 2004/2005 & 1435,4 & \multicolumn{3}{|c|}{ Tendente a Chuvoso (TC) } \\
\hline Primavera-Verão - 2003/2004 & 1127,7 & \multicolumn{3}{|c|}{ Normal (N) } \\
\hline Primavera-Verão - 2002/2003 & 1267,6 & \multicolumn{3}{|c|}{ Normal $(\mathrm{N})$} \\
\hline Primavera-Verão - 2001/2002 & 1496,9 & \multicolumn{3}{|c|}{ Tendente a Chuvoso (TC) } \\
\hline Primavera-Verão - 2000/2001 & 1086,5 & \multicolumn{3}{|c|}{ Normal $(\mathrm{N})$} \\
\hline Primavera-Verão - 1999/2000 & 1251,4 & \multicolumn{3}{|c|}{ Normal (N) } \\
\hline Primavera-Verão - 1998/1999 & 1416,3 & \multicolumn{3}{|c|}{ Tendente a Chuvoso (TC) } \\
\hline Primavera-Verão - 1997/1998 & 1232,3 & \multicolumn{3}{|c|}{ Normal (N) } \\
\hline Primavera-Verão - 1996/1997 & 1242,2 & \multicolumn{3}{|c|}{ Normal $(\mathrm{N})$} \\
\hline Primavera-Verão - 1995/1996 & 1352 & \multicolumn{3}{|c|}{ Normal $(\mathrm{N})$} \\
\hline Primavera-Verão - 1994/1995 & 1548,5 & \multicolumn{3}{|c|}{ Tendente a Chuvoso (TC) } \\
\hline Primavera-Verão - 1993/1994 & 1069 & \multicolumn{3}{|c|}{ Normal (N) } \\
\hline
\end{tabular}

\section{EMBRAPA}

Os dados de precipitação da série histórica contidos na Estação Meteorológica da EMBRAPA que também abrange um período de 21 anos hidrológicos, apresentaram uma média de $1.128,90 \mathrm{~mm}$. Os resultados obtidos apontaram para uma variabilidade no comportamento pluviométrico do período como é demonstrado no Gráfico 3.

Desta forma, o número de ocorrência com maior ordem de frequência também ficou dentro dos valores com desvios variando entre $-15 \%$ a $+15 \%$ da média e classificados como semestres Normais (N), representando percentualmente $71,42 \%$ dos 21 anos estudados. Apresentaram-se como normais os seguintes anos; 1993/1994, 1994/1995, 1995/1996, 1996/1997, 1997/1998, 1999/2000, 2001/2002, 2002/2003, 2003/2004, 2004/2005, 2005/2006, 2006/2007, 2008/2009, 2009/2010 e 2011/2012. 


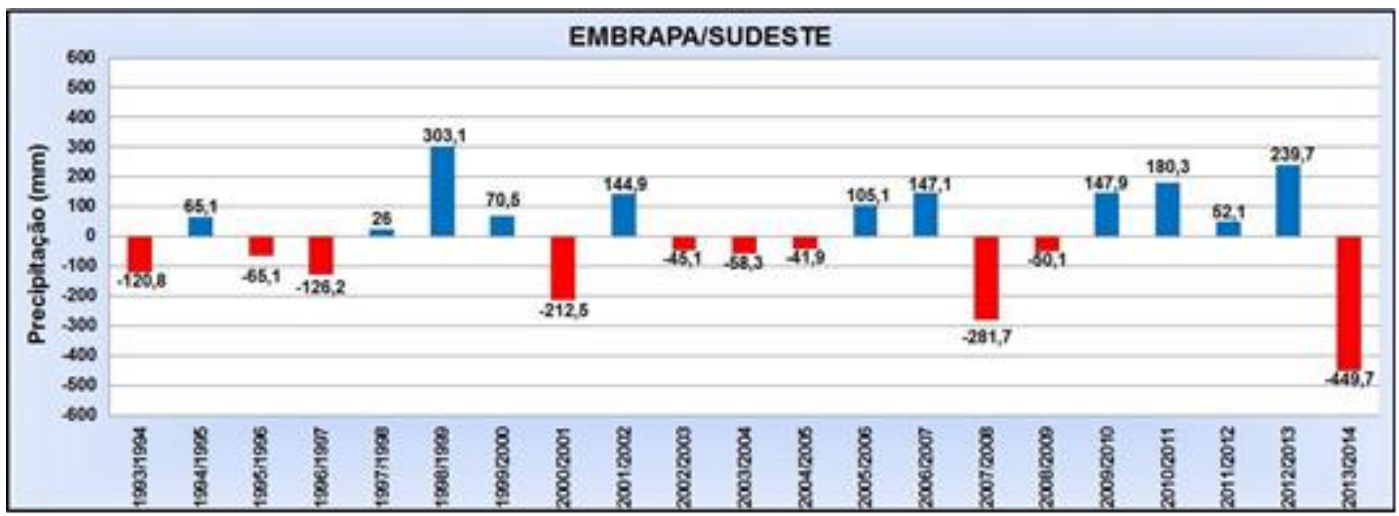

Gráfico 3 - Desvios em relação à média dos dados pluviométricos registrados na Estação Sinótica do EMBRAPA/Sudeste no período de 1993/94 a 2013/14

A segunda maior ordem de frequência ficou na classe Tendente a Chuvoso (TC) representando percentualmente $14,28 \%$ e a terceira maior ordem ficou na classe Tendente a Seco (TS), representando 9,52\%.

Por último a quarta ordem de frequência também ficou na classe Seco (S), correspondendo percentualmente $4,76 \%$ com apenas uma única manifestação respectivamente em toda série histórica de 21 anos.

A Tabela 4 a seguir sintetiza o número de ocorrência que os períodos chuvosos se classificaram e qual foi a ordem de frequência e sua percentagem ao longo dos 21 anos, dentro das categorias habituais ou atípicas.

A estação da EMBRAPA/Sudeste registrou no período chuvoso de 2013/2014 679,2 mm de precipitação, situando-se devido ao desvio negativo em relação a média na condição de Ano Seco (S). A análise dos 21 anos da série dessa estação não identificou qualquer evento semelhante a este; porém, eventos pluviométricos próximos a Seco ocorreram durante alguns anos como nos semestres de 2000/2001 e 2007/2008, que apresentaram valores negativos. Além desse ano padrão Seco (2013/2014), também não foi identificado na série nenhum semestre Chuvoso, apenas ocorreram eventos com desvio positivos significativos como é o caso dos anos de 1998/1999, 2010/2011 e 2012/2013 como Tendente a Chuvoso (Tabela 5).

Tabela 4 - Frequência porcentual dos tipos de classificação (1993/94 - 2013/14)

\begin{tabular}{|l|c|c|c|}
\hline \multicolumn{1}{|c|}{ Tipo } & $\begin{array}{c}\text { Número de } \\
\text { Ocorrência }\end{array}$ & Porcentagem & $\begin{array}{c}\text { Ordem de } \\
\text { Frequência }\end{array}$ \\
\hline N - Normais & 15 vezes & $71,42 \%$ & 10 \\
\hline TC - T. Chuvosos & 3 vezes & $14,28 \%$ & 20 \\
\hline C - Chuvosos & 0 vez & $0 \%$ & - \\
\hline TS - T. Secos & 2 vezes & $9,52 \%$ & 30 \\
\hline S - Secos & 1 vez & $4,76 \%$ & 20 \\
\hline
\end{tabular}


Tabela 5 - Classificação dos anos e seus padrões para estação EMBRAPA/Sudeste

\begin{tabular}{|c|c|c|}
\hline ANOS & TOTAL & Classificação \\
\hline $\begin{array}{l}\text { MÉDIA 1993-94/2013-14 } \\
\text { (Estação EMBRAPA) }\end{array}$ & 1129 & $(\mathrm{~N}) \quad(\mathrm{TC})$ \\
\hline Primavera-Verão - 2013/2014 & 679,2 & Seco (S) \\
\hline Primavera-Verão - 2012/2013 & 1368,6 & Tendente a Chuvoso (TC) \\
\hline Primavera-Verão - 2011/2012 & 1181 & Normal (N) \\
\hline Primavera-Verão - 2010/2011 & 1309,2 & Tendente a Chuvoso (TC) \\
\hline Primavera-Verão - 2009/2010 & 1276,8 & Normal (N) \\
\hline Primavera-Verão - 2008/2009 & 1078,8 & Normal (N) \\
\hline Primavera-Verão - 2007/2008 & 847,2 & Tendente a Seco (TS) \\
\hline Primavera-Verão - 2006/2007 & 1276 & Normal (N) \\
\hline Primavera-Verão - 2005/2006 & 1234 & Normal (N) \\
\hline Primavera-Verão - 2004/2005 & 1087 & Normal (N) \\
\hline Primavera-Verão - 2003/2004 & 1070,6 & Normal (N) \\
\hline Primavera-Verão - 2002/2003 & 1083,8 & Normal (N) \\
\hline Primavera-Verão - 2001/2002 & 1243,8 & Normal (N) \\
\hline Primavera-Verão - 2000/2001 & 916,4 & Tendente a Seco (TS) \\
\hline Primavera-Verão - 1999/2000 & 1199,4 & Normal (N) \\
\hline Primavera-Verão - 1998/1999 & 1432 & Tendente a Chuvoso (TC) \\
\hline Primavera-Verão - 1997/1998 & 1154,9 & Normal (N) \\
\hline Primavera-Verão - 1996/1997 & 1002,7 & Normal (N) \\
\hline Primavera-Verão - 1995/1996 & 1063,8 & Normal (N) \\
\hline Primavera-Verão - 1994/1995 & 1194 & Normal (N) \\
\hline Primavera-Verão - 1993/1994 & 1008,1 & Normal (N) \\
\hline
\end{tabular}

Conforme os dados demonstram, o padrão atmosférico da área de estudo é caracterizado por uma habitualidade que se expressa através dos índices situados na média (Normal) da série histórica ou próximos (Tendente a Chuvoso ou Tendente a Seco) a ela. Essa habitualidade sofre interrupção apenas no período hidrológico 2013/2014 quando os índices anotados nas duas estações alcançam patamar distante desse padrão (Seco), indicando que as condições atmosféricas não estiveram regidas pelos mesmos parâmetros que habitualmente se manifestam na área de estudo a partir da organização sinótica observada, pois, ainda que por sete vezes as classes estabelecidas na metodologia adotada não tenham sido as mesmas na classificação dos anos, estiveram próximas, confirmando a força da habitualidade atmosférica nessa porção da superfície terrestre, destacando, por conseguinte, mais uma vez, toda atenção que é dada ao período específico 2013/2014 por sua situação ímpar na série considerada no estudo. 


\section{EVENTOS OCORRIDOS DURANTE O PERÍODO CHUVOSO DE 2013/2014}

Foi elaborado um gráfico da distribuição mensal da precipitação para o período de outubro/2013 a março/2014 em paralelo a seleção de reportagens que enfatizassem todas as repercussões ao longo do período (Tabela 6).

Tabela 6 - Reportagens sobre os eventos climáticos ocorridos em São Carlos/SP no ano hidrológico 2013/2014

\begin{tabular}{|c|c|c|}
\hline JORNAL & DATA & REPERCUSSÕES/TÍTULO \\
\hline Primeira Página & $23 / 10 / 2013$ & $\begin{array}{l}\text { Chuvas traz prejuízo e estragos à } \\
\text { cidade }\end{array}$ \\
\hline A Folha & $23 / 10 / 2013$ & Chuva causa prejuízo na cidade \\
\hline Primeira Página & $23 / 10 / 2013$ & $\begin{array}{l}\text { Prefeitura estima prejuízo de } \mathrm{R} \$ 2 \\
\text { milhões com chuva }\end{array}$ \\
\hline A Folha & $23 / 10 / 2013$ & $\begin{array}{l}\text { Prefeito decreta estado de emergência; } \\
\text { prejuízo de } \mathrm{R} \$ 2 \text { milhões. }\end{array}$ \\
\hline A Folha & $08 / 11 / 2013$ & $\begin{array}{l}\text { Chuvas provocam queda de árvores em } \\
\text { São Carlos }\end{array}$ \\
\hline Primeira Página & $15 / 0$ & $\begin{array}{l}\text { Chuva provoca queda de telhado no } \\
\text { Aracy }\end{array}$ \\
\hline Primeira Página & $31 / 01 / 2014$ & $\begin{array}{l}\text { Agricultores e produtores sofrem com o } \\
\text { calor e falta de chuva }\end{array}$ \\
\hline Primeira Página & $31 / 01 / 2014$ & $\begin{array}{l}\text { Temperaturas em janeiro estão } 4^{\circ} \mathrm{C} \\
\text { acima da média em São Carlos }\end{array}$ \\
\hline Primeira & $01 / 0$ & $\begin{array}{l}\text { Baixa umidade exige cuidados com a } \\
\text { saúde }\end{array}$ \\
\hline Primeira Página & $05 / 02 / 2014$ & Saae projeta racionamento de água \\
\hline Primeira Página & $05 / 02 / 2014$ & $\begin{array}{l}\text { São Carlos poderá ter racionamento de } \\
\text { água }\end{array}$ \\
\hline Primeira Página & $06 / 02 / 2014$ & $\begin{array}{l}\text { Altas temperaturas e estiagem exigem } \\
\text { uso racional de água e energia }\end{array}$ \\
\hline Primeira Página & $06 / 02 / 2014$ & $\begin{array}{l}\text { Verão atípico obriga uso racional de } \\
\text { água e energia em São Carlos }\end{array}$ \\
\hline Primeira Página & $07 / 02 / 2014$ & $\begin{array}{l}\text { Venda de galões de água aumentam } \\
\text { por conta do calor }\end{array}$ \\
\hline Primeira Página & $07 / 02 / 2014$ & $\begin{array}{l}\text { Clima quente aquece o comércio no } \\
\text { verão }\end{array}$ \\
\hline Primeira Página & $09 / 02 / 2014$ & $\begin{array}{l}\text { Estiagem faz aumentar } 266 \% \\
\text { número de queimadas no Estado }\end{array}$ \\
\hline Primeira Página & $09 / 02 / 2014$ & $\begin{array}{l}\text { Sudeste e Sul deveriam racionar } 5 \% \text { da } \\
\text { energia }\end{array}$ \\
\hline Primeira Página & $11 / 02 / 2014$ & $\begin{array}{l}\text { Setor cítrico estima queda na produção } \\
\text { do suco de laranja }\end{array}$ \\
\hline
\end{tabular}




\begin{tabular}{|c|c|l|}
\hline Primeira Página & $11 / 02 / 2014$ & $\begin{array}{l}\text { Falta de chuva compromete produção } \\
\text { industrial no interior paulista }\end{array}$ \\
\hline Primeira Página & $14 / 02 / 2014$ & $\begin{array}{l}\text { Frente fria chega ao Sudeste e deve } \\
\text { aliviar o calor e o tempo seco }\end{array}$ \\
\hline Primeira Página & $14 / 02 / 2014$ & $\begin{array}{l}\text { Perdas na produção rural por causa do } \\
\text { calor e da seca já afetam preços }\end{array}$ \\
\hline Primeira Página & $25 / 02 / 2014$ & $\begin{array}{l}\text { Cepta pede prorrogação da piracema } \\
\text { por mais 1 mês no Rio Mogi Guaçu }\end{array}$ \\
\hline Primeira Página & $21 / 03 / 2014$ & $\begin{array}{l}\text { Seca atinge alimentos e pressiona } \\
\text { inflação }\end{array}$ \\
\hline Primeira Página & $21 / 03 / 2014$ & $\begin{array}{l}\text { Crise no setor sucroalcooleiro atinge } \\
\text { São Carlos }\end{array}$ \\
\hline
\end{tabular}

O Gráfico 4 mostra como a precipitação ficou distribuída mensalmente no período de 2013-2014 em relação às normais climatológicas (1960-1990) mensais do INMET.

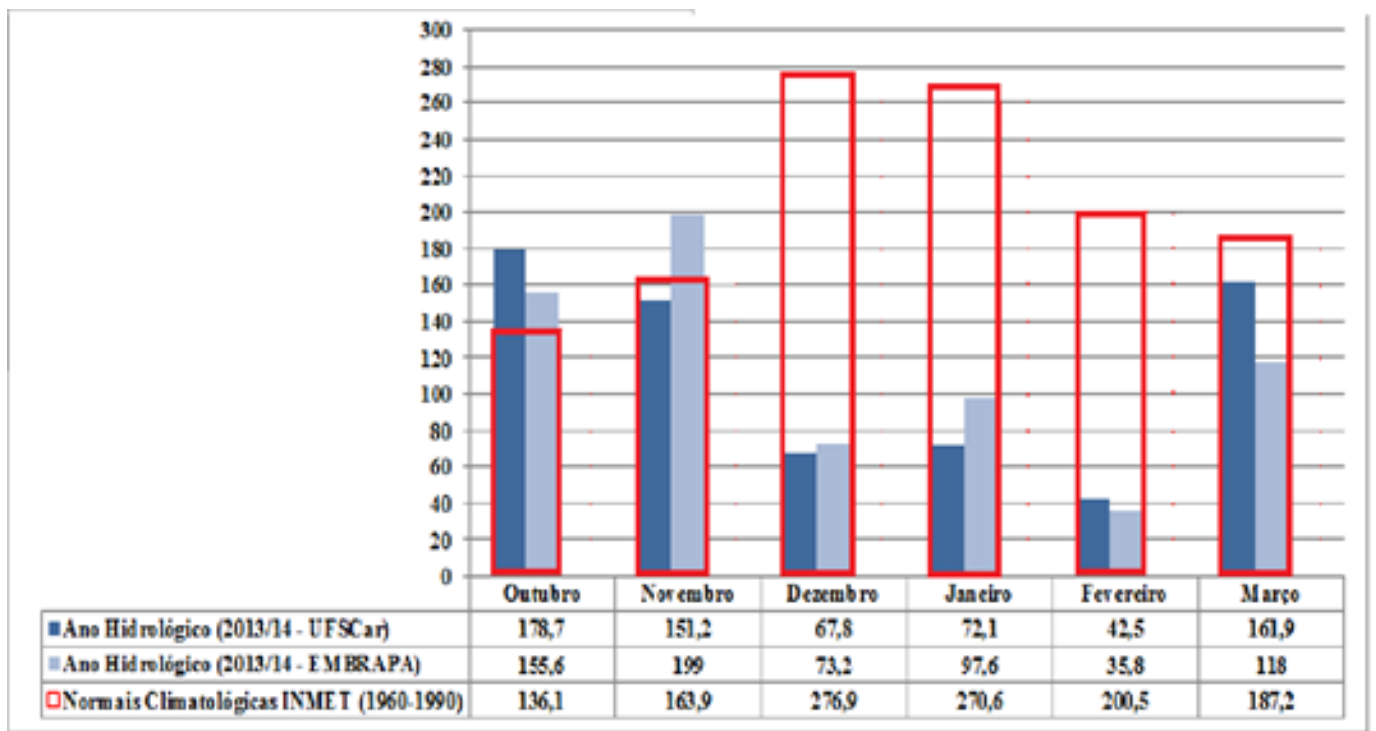

Gráfico 4 - Comparação entre Precipitação de 2013/2014 nas estações INMET/UFSCar e EMBRAPA frente a média histórica do INMET (1961-1990)

Nota-se pelo Gráfico 4 que nos meses de outubro e novembro a precipitação apresentou valores acima da média. A repercussão disto foi observada na inundação da área central do município de São Carlos (Figuras 2 e 3) causando sérios prejuízos para a população e comerciantes. Obviamente a impermeabilização do solo e a canalização dos rios que cortam a cidade cooperaram com o excesso de chuva 


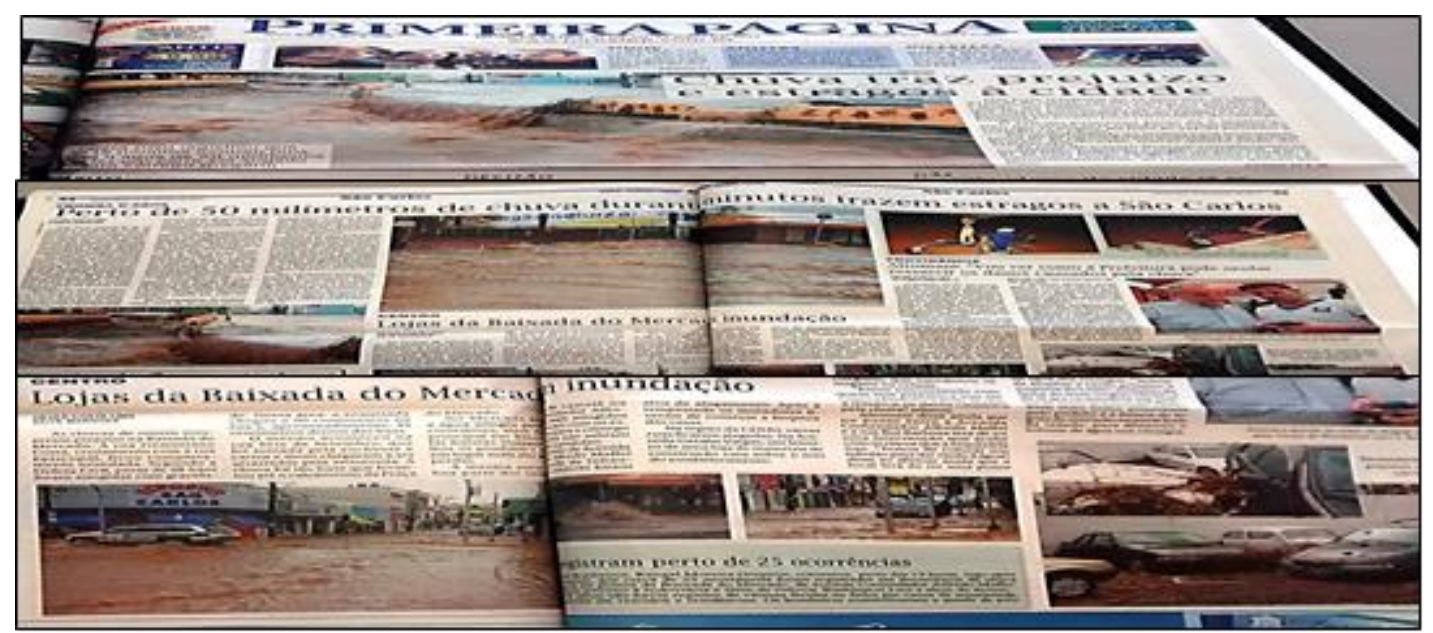

Figura 2 - Reportagens sobre a inundação na área central de São Carlos/SP ocorridas em outubro e novembro de 2013

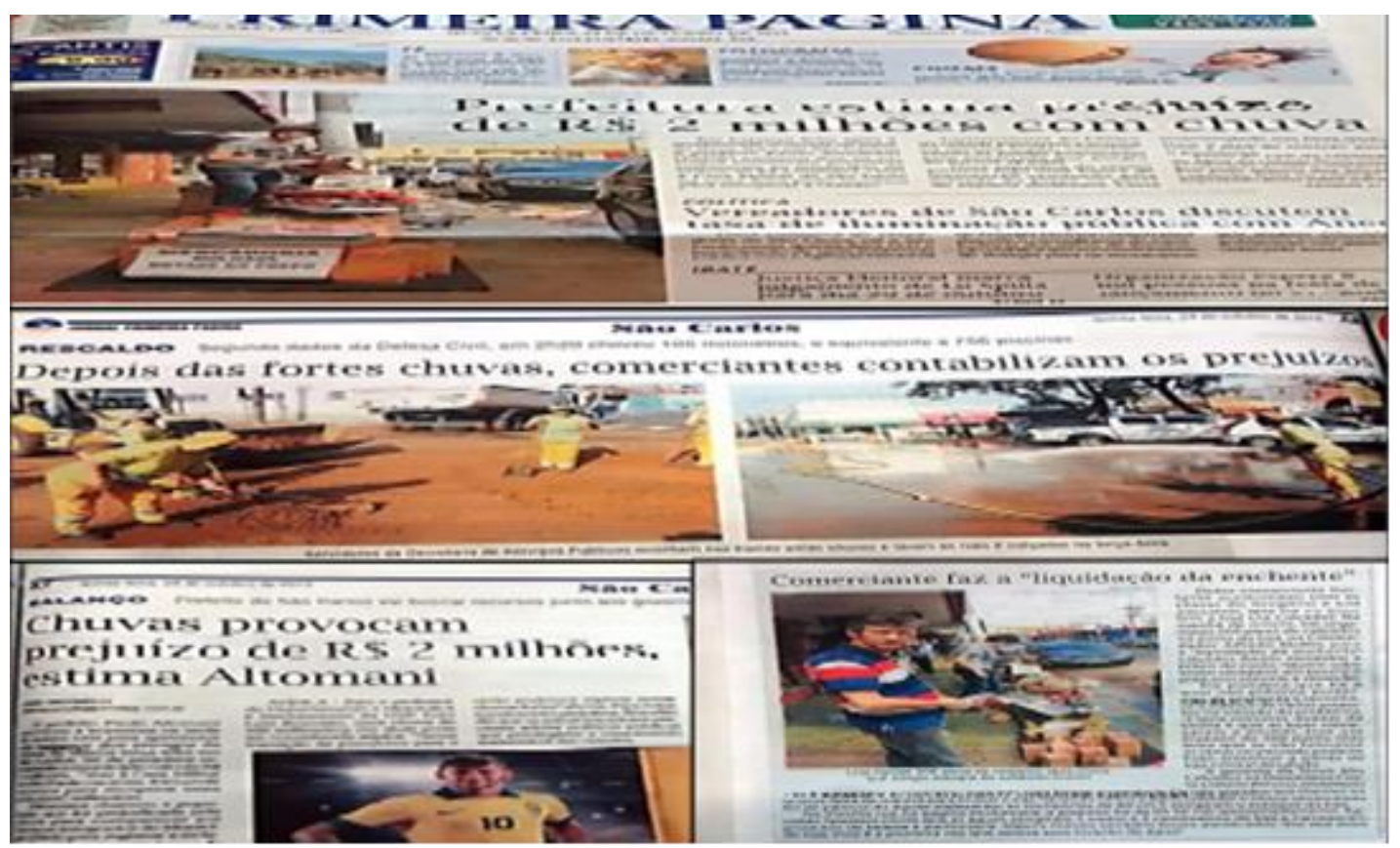

Figura 3 - Reportagens sobre transtornos da inundação no centro de São Carlos/SP ocorridas em outubro e novembro de 2013

Entre dezembro/2013 e março/2014, nos meses correspondentes ao verão (dezembro, janeiro e fevereiro), ou seja, aqueles com expectativa de maiores valores de precipitação, observou-se valores significativamente abaixo da média. Segundo Coelho et al (2016), esse deficit de precipitação na região Sudeste do Brasil, deveu-se ao estabelecimento excepcional de um sistema de alta pressão, no caso a ASAS, atuando mais ao oeste do oceano Atlântico subtropical. Esse bloqueio impediu a entrada do fluxo de umidade vindo da Amazônia e dos sistemas frontais para região e, assim, não se consumou a configuração da ZCAS e seus eventos correspondentes. 
Em face disto, a ausência da ZCAS nesse período em específico fez com que as chuvas diminuíssem significativamente, ocasionando sensíveis impactos sobre as atividades antrópicas, sociedade e meio ambiente, pois, eventos dessa natureza possuem a capacidade de afetar drasticamente áreas ambientais devido ao deficit na recarga dos recursos hídricos ou no favorecimento das condições propícias ao aumento no número de queimadas. Além dos problemas ambientais dessa natureza, a seca também gerou um grave problema social, principalmente nos setores que utilizam o recurso hídrico para fins econômicos diversos como abastecimento de água, irrigação, indústrias, produção de energia, entre outros, gerando um quadro de crise.

Para Marengo et al (2015) a "crise hídrica" de 2014, serviu como um sinal de alerta às autoridades públicas, despertando-as para a dimensão e abrangência dos impactos sofridos pelos setores socioeconômicos devido à falta de preparo na implementação de medidas de mitigação e gerenciamento ocupados com a finalidade de diminuir a vulnerabilidade do homem frente aos eventos climáticos extremos. (Figuras 4 e 5). 


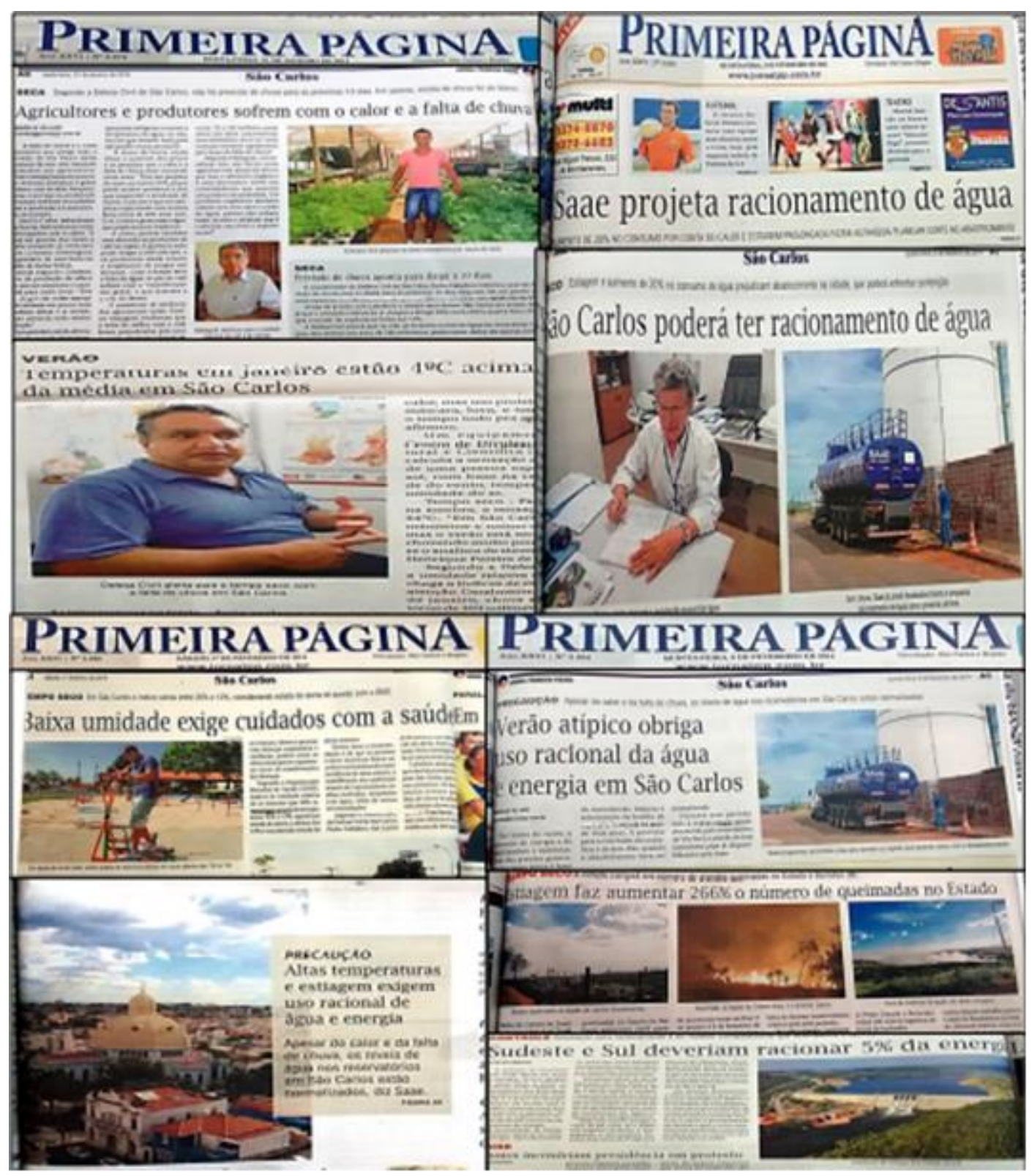

Figura 4 - Reportagens destacando os problemas causados pela queda da precipitação durante o ano hidrológico 2013/2014 


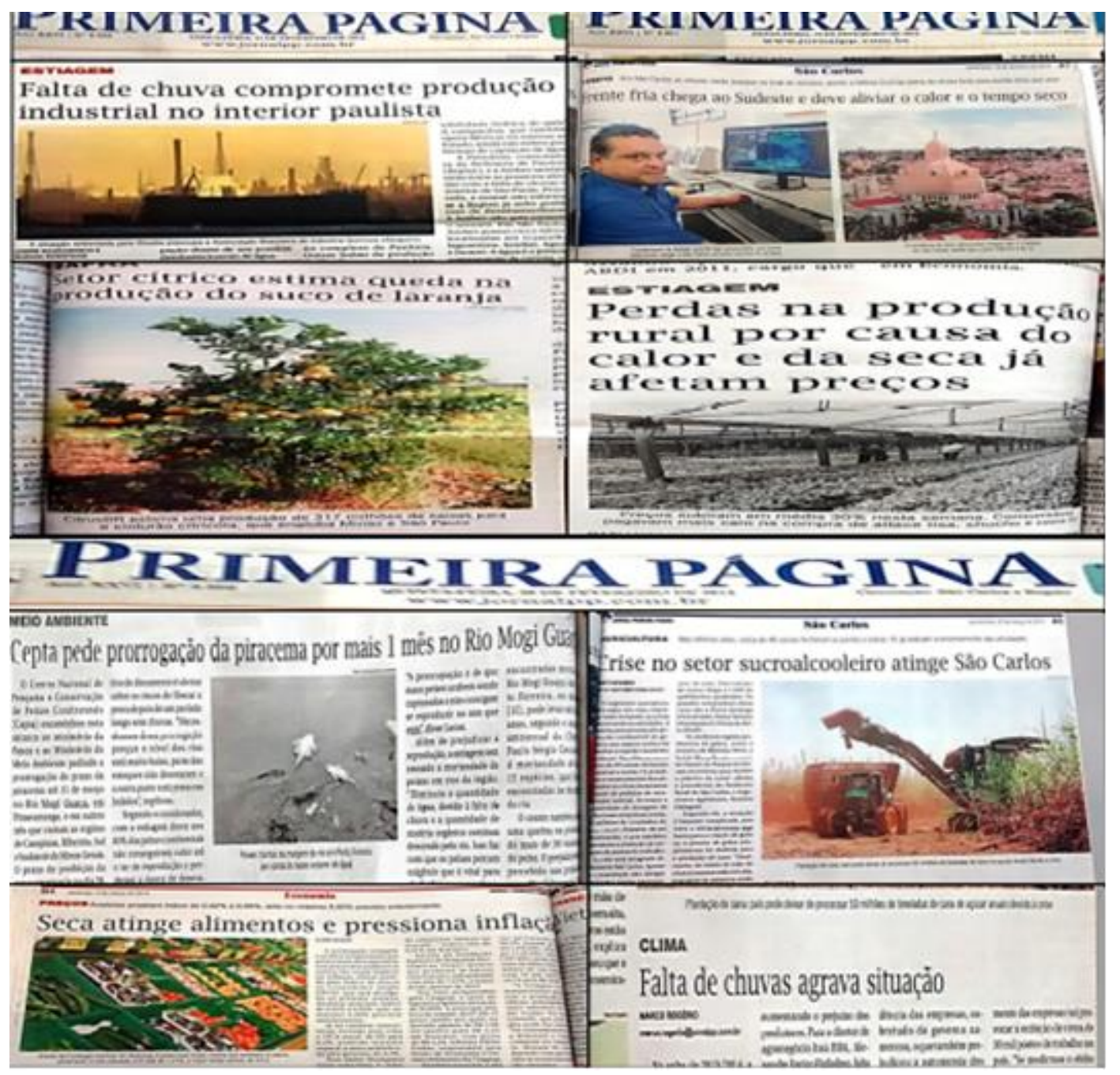

Figura 5 - Reportagens com a repercussão dos efeitos da queda da precipitação em São Carlos/SP no ano hidrológico 2013/2014

\section{CONCLUSÃO}

Conforme o estudo desenvolvido demonstrou, o comportamento da precipitação ao longo dos últimos vinte e um anos na região de São Carlos/SP manteve-se próximo da média habitual no que diz respeito a precipitação, no entanto, o ano hidrológico (outubro a março) de 2013/2014 avaliado, distanciou-se dessa tendência, apresentando índice pluviométrico condizente com a categoria Ano Seco (S) da metodologia utilizada que admitia cinco classes (ano normal, ano seco, ano chuvoso, ano tendente a seco, e, ano tendente a chuvoso). Os dados analisados e as informações noticiadas pelos jornais corroboraram com a pesquisa desenvolvida atestando a vulnerabilidade da sociedade frente aos eventos climáticos extremos.

A estação do INMET/UFSCar registrou no ano hidrológico de 2013/2014 uma precipitação total de $674,2 \mathrm{~mm}$ que se situa nos índices de um Ano Seco diante da média da série histórica ser $1.225,46 \mathrm{~mm}$. A estação da 
EMBRAPA/Sudeste registrou uma precipitação total de $679,2 \mathrm{~mm}$ que Ihe enquadra na mesma condição da anterior (Ano Seco) em face da média da série histórica estar situada em 1128,90 mm.

Obviamente esses índices tiveram reflexo nos diversos setores socioeconômicos e ambientais na região de São Carlos/SP, no entanto, atentando para as informações contidas na série histórica, é possível afirmar que não seriam suficientes para criar o quadro de gravidade que foi amplamente propalado pela mídia e corroborado pelas autoridades públicas, posto que nos anos hidrológicos anteriores os índices registrados estiveram próximos da média histórica permitindo a recarga dos reservatórios em paralelo a manutenção do abastecimento cotidiano; sobretudo se os órgãos públicos ou privados ocupados com o abastecimento de água na região tivessem dimensionado a demanda/consumo do recurso e previsto situações dessa natureza - diminuição pontual do índice pluviométrico - em suas simulações e planejamento estratégico.

Pelo que se pode observar nos dados coletados nas duas estações consultadas, tem-se na série histórica uma média aproximada de $69 \%$ de Anos Normais onde o índice pluviométrico ficou muito próximo ou igual à média da série histórica, 15\% de Anos Tendentes a Chuvosos, 9,5\% de Anos Tendentes a Secos e 4,7\% de Anos Secos.

De posse desses dados é possível afirmar que a habitualidade do padrão atmosférico que prevalece na área de estudo transita em patamares que dificilmente impõe uma carência na oferta de água, a salvo que a situação vivenciada no ano hidrológico $2013 / 2014$ se repita com mais frequência nos anos que se seguem.

\section{REFERÊNCIAS BIBLIOGRÁFICAS}

ANDRÉ, Í. R. N. Algumas considerações sobre mudanças climáticas e eventos atmosféricos severos recentes no Brasil. Climatologia e Estudos da Paisagem, v.1, 2006, p. 01-09.

BARBOSA, J. P. M. Mudanças climáticas e distribuição espacial da precipitação na Serra do Mar - análise a partir de séries históricas de precipitação e sistemas de informação geográfica (SIG). Caminhos da Geografia, Uberlândia, v. 8, 2007, p. 67-81.

BRAIDO, L. M. H.; TOMMASELLI, J. T. G. Caracterização climática e dos anos extremos (chuvoso e seco): seus efeitos na produção de cana-de-açúcar, milho e soja para a região do Pontal do Paranapanema-SP. Revista Formação, v. 1, 2010, p. 13-34.

CARMO R. L.; ANAZAWA, T. M.; JOHANSEN, I. C. Seca nas metrópoles: materialização de um desastre anunciado. Waterlat-Gobacit Network Working Papers - Thematic Area Series SATAD - TA8 - Water-related Disasters, v. 1, 2014, p. 91-109.

CENTRO DE PREVISÃO DO TEMPO E ESTUDOS CLIMÁTICOS. Síntese sinótica do mês de fevereiro de 2014. Cachoeira Paulista, 2014. Disponível em:<http://www.cptec.inpe.br/noticias/noticia/125973>. Acesso em: 17 jan. 2017. 
COELHO, C. A. S.; CARDOSO, D. H. F.; FIRPO, M. A. F.. A seca de 2013 a 2015 na região sudeste do Brasil. Climanálise - Edição Especial de 30 anos, p. 55-61, 2016.

CUNHA, G. R. Meteorologia - Fatos e mitos 1. Passo Fundo: EMBRAPA, 1997.

INSTITUTO NACIONAL DE METEOROLOGIA. Normais climatológicas de precipitação 1960-1990. Brasília, 2014. Disponível em: <http://www.inmet.gov.br/portal/index.php?r=clima/normaisClimatologicas >. Acesso em: 18 jan. 2017.

MARENGO J. A; NOBRE, C. A.; SELUCHI, M. E.; CUARTAS, A.; ALVES, L. M.; MENDIONDO, E. M.; OBREGÓN, G.; SAMPAIO, G. A seca e a crise hídrica de 2014-2015 em São Paulo. Revista USP, São Paulo. n. 106, p. 31-44, 2015.

MONTEIRO, C. A. de F. Dinâmica Climática e as chuvas no Estado de São Paulo. Estudo geográfico sob forma de atlas. São Paulo: Universidade de São Paulo/Instituto de Geografia, 1973.

. O Clima e a organização do espaço no Estado de São Paulo: problemas e perspectivas. São Paulo, Série Teses e Monografias, 28, USP/IGEOG, 1976.

Clima e Excepcionalidade: conjunturas sobre o desempenho da atmosfera como fenômeno climático. Florianópolis: UFSC, 233p. 1991.

MOURA, M. O.; ZANELLA, M. E. Escolha de "Anos-Padrão" para o estudo do conforto térmico em Fortaleza, CE: verificação de critérios. Revista Geonorte, v. 1 , p. 547-560, 2012.

NEVES, G. Z. F. Variabilidade da radiação em ondas longas em uma cidade de porte médio: experimentos nos espaços livres em São Carlos- SP. 2014. Dissertação (Mestrado em Ciências da Engenharia Ambiental) - Escola de Engenharia de São Carlos, Universidade de São Paulo, São Carlos, 2014.

NIMER, E. Climatologia do Brasil. IBGE, Rio de Janeiro, 422p, 1979.

PEIXOTO, J. P.: As Variações do clima e o ambiente - o homem, o clima e o ambiente II. Lisboa: Secretaria de Estado do Ambiente e dos Recursos Naturais, 1987.

QUADROS M. F. L.; DIAS, M. A. F. S.; HERDIES, D. L.; GONÇALVES, L. G. G. Análise climatológica da precipitação e do transporte de umidade na região da ZCAS através da nova geração de reanálises. Revista Brasileira de Meteorologia, v.27, p.152-162, 2012.

SILVA, J. M. O.; SILVA, E. V. Utilização dos anos padrões para a caracterização pluviométrica na bacia hidrográfica do rio Pirangi/Ceará. Revista Geonorte, v. 3, 2012, p. 1358-1369.

SOARES, L. P.; ZANELLA, M. E. Eleição de anos-padrão para a caracterização climática do Estado do Ceará. In: X SIMPÓSIO BRASILEIRO DE CLIMATOLOGIA GEOGRÁFICA, 2014, Curitiba. Anais...Curitiba: 2014, p. 2468-2479.

TAVARES, A. C. Critérios de escolha de anos padrões para análise rítmica. Revista Geografia, v.1, 1976. p.79-87. 